\title{
Russian Environmentalist Oleg Yanitsky: Reflections on My Own Life-Story
}

\author{
YANITSKY Oleg Nikolaevich* \\ Doctor of Philosophy, Professor, Chief Researcher, Dept. of History and Theory, Federal Center of Theoretical \\ and Applied Sociology of the Russian Academy of Sciences
}

\author{
*Corresponding Author:YANITSKY Oleg Nikolaevich, Doctor of Philosophy, Professor, Chief \\ Researcher, Dept. of History and Theory, Federal Center of Theoretical and Applied Sociology of the \\ Russian Academy of Sciences
}

\begin{abstract}
The article presents the reflections on my own life-story from a set of positions: an impact on it of my 'big family', from viewpoint of unintended changes in global and national political context and my own oscillations between fine arts, urban studies, sociology and environmentalism. From early childhood I've a lucky chance to be in the midst of national and some global events and its creators and carriers. These events always hadbeen characterized by critical overtone and sudden risks. Being unconsciously globally oriented I'm at the same time had maintained my deepinclusion in local lifeof my country as a landscape painter and a permanent traveler. Later on, being an architect and urban theorist I suddenly opened for me a new research area: environmental sociology. I see Z. Bauman, U. Beck, M. Castells, R. Pahl and A. Touraine as well as V. Vernadsky, D. Lichachev, mygrandfather F. Yanitsky and my aunt V. Schmidt as my life-tutors. Throughout my life I'd been under the impact of my 'big family' very diversified one from the socialist-revolutionaries to charity activists, and from historians tomathematics and biologists. The lessons of my life-story are as following: the 'big family' as a part of a person's life-story should be protected by all means; the mean of its maintenance is a permanent one-to-one communication by any means; in the run of life-span its role is changing but remains important; the same should be said in relation of our small motherlands, otherwise a global community is at risk to become a Brownian movement; and a diversity has to be not only in the nature and social life, the diversity is an inseparable feature ofan individual experience.
\end{abstract}

Keywords: Big Family, Diversity, Environment, Globalization, Individual, Interdisciplinary Approach, LifeStory, Natural Sciences, Sociology

\section{INTRODUCTION}

I was born in Moscow (the Soviet Union) in 1933. My father was a historian and geographer and my mother was a doctor. After graduating from secondary school in 1951 I entered Moscow Architectural Institute and graduate from it in 1957. Then I worked in the Academy of architecture of the USSR, after then - in the Institute of International Labor movement of the Academy of sciences of the USSR. In the late 1960s, I'd initiated an establishment of the Research Committee on Social Problems of Urbanism of the Soviet Sociological Association. In parallel, I'd participated in many international research projects including the project 'Cities of Europe: The Public's Role in Shaping the Urban Environment' in the frames of the UNESCO's program 'Man and the Biosphere'. After then, I had worked in the European Bank of Research and Development as a 'friendly adviser'. In 1970 together with M. Castells, R. Pahl, J. Musil, and some other European sociologists I'd participated in the establishment of the Research Committee on Urban and Regional Development of the International Sociological Association, one of the organizers of the Research Network on Social Movements of the European Sociological Association. As a visiting professor, I had been in the MIT, the Great Britain and Finland research centers. Now I'm an ordinary professor at the Federal Research Center of Russian academy of sciences and the member of the Russian Society of Sociologists. I'm the author of about 20 monographs (in Russian and English) and more than 500 articles in Russian, English, German, French and Chinese. The main realms of my interest are the globalization processes, urban studies, risk research, grassroots and social movements. I'm still an adherent of the Chicago school of Human Ecology and see Zygmunt Bauman, Ulrich Beck, Manuel Castells, Raymond Pahl and Alaine Touraine as my tutors in sociology. As to Russian scientists and practitioners, I'll mention them later 
because many of them are not sociologists and therefore not known to the majority of western and eastern sociologists and humanitarians. It may be a little surprising but I see some outstanding Russian artists (mainly painters, but not only) as my tutors as well. But this abbreviated vita says nearly nothing neither about me not about my life-story.

\section{AIMS AND METHODS}

The main idea of this article is to look back and to try to understand the relationships between the past, present and a future in my professional life. As an environmentalist (in the widest sense of the word), I am in particular is interested in the relationships between given conditions never mind be ita family, cultural tradition or political regime and my own possibilities to overcome them in the tracing of my own life-story. In my case it has been especially important due to extreme diversity of my 'human surroundings.' Each of them might or might not to substantially change my life trajectory. It should be taken into account that during my life-span a political regime is seriously or even radically changed at least three times. In some cases it had been a king of fluctuations ofoverall political context only, in others it touched me directly. Accordingly, in one cases a big family had been capable to protect me in a manner but in others it had been powerless, and I must take a decision by myself.

The reverse side of the same coin is my permanent presence in a global context. This statement may be seen a very ambitious but it is quite so. Besides my early interest in global geography - my father talk me about the era of great geographical discoveries, from about four years old I'd been in the midst of true global events of a paramount economic, political and cultural importance (see below). Let me give to the reader only one example. My periodical presence in the UNESCO's headquarters in Paris duringabout 15 years meant that to be at the crossroads of numerous world contacts. Such world organizations are a true melting pot. Initially, my western colleagueslooked at me a little suspicious but later we'd become true colleagues and friends with many of them.

As to methods, I'm inclined to qualitative methods of research. I well understand the importance of operating with Big Data but in my very case they were useless. By a habit of mind and behavior I'm a miser (flay-flint). My table and shelves are crammed with note-books, pieces of paper covered with writing, photos, notes, etc. Speaking seriously, my personal dossier is contained of the archives of my family including my grandfather, Feodor Yanitsky'sletters from the Russian-Japan (1904-05) and from the First World (1914-17) wars; a vast correspondence of my grandmother ElizavetaYanitskaya with her daughter and sisters; the letters of my uncle, well-known Soviet polar researcher Otto Schmidt; the works and letters of his wife Vera Schmidt and many other human documents. In my big family have been two persons who had been the participants of the WWII from the very beginning to its end in 1945. Besides, as a researcher of Russian grassroots and environmental and other social movementsI'd gathered about 400 in-depth interviews with their activists as well as with their counterparts that is with businessmen, municipal administrations, members of counter-movements and many others. Finally, a cousin of my father, PiotrJanitzky from the US, visited Moscow in 2002 and supplied me with very important dataconcerning our'big family' life in 1900s. In all possible cases I interrelated my research findings with already published facts and data in Russian and foreign historical and epistolary literature. Some of the my archive materials are on the Official Site of the abovementioned Federal Research Center for Sociology, others I transferred to state and private archives. From 1980s onwards I was developing the concept of a primary eco-structure that combined the past, present and a future of an individual (Yanitsky, 2012).

\section{INTELLECTUAL ATMOSPHERE IN BIG FAMILY}

To begin with, I'd say that a majority of its participants hadn't been of one-sided interests.My father, the historian and geographer dreamed to become a pianist and even a conductor. My mother and her daughter dreamed to be the artists. And it is not a singular case. My Aunt Vera Schmidt initially intended to be a doctor and then she became a psychoanalyst who in 1920s worked with Z. Freud (Schmidt, 1924). Being a student Vera had organized a home circle titled the 'Intellectual Enjoyment.' The principles of children's upbringing laid down at one of her presentation at the sittings of this circle are still valid. Then she turned to psychoanalysis as a science combining this work with propaganda of healthy life. Her psychoanalytic works have been published in Russian fifty years later only. My grandmother (from the father's side) had initially been a zemsky doctor in Russian province then, a tubercular peadiatristand afterthen a civic activist. She and her daughter Vera had been the most democratically-oriented members of my family on the eve of the revolutionary events in Russia 
in 1905-07 and later. Some members of my big family at the turn of the centuries had been more radical-oriented. For their revolutionary activitytwo of them had been political convicts. One of them talented chemist and socialist-revolutionary spent in prison 11 years (six of them in the irons) and wrote there a book titled 'The Naturalist Views of Johann Goethe' issued two years after his death in the run of civil war.

The life-story of Otto Schmidt deserves special attention. Being from the family of a petty trader Otto graduated from the Kiev University as a mathematician in 1916, he immediately included in the struggle for the rights of junior university teachers. The matter ended by his and his wife's Vera work in the first Bolshevik government in the 1918-19s. Otto as a mathematician worked in the department dealt with financial turnover and Vera as a clerk at the People's Commissariat of education. It is difficult to count all posts of O. Schmidt but some of them should be mentioned: the head of the State science department (Glavnauka), the head of the Northern Sea Root department, the head ofthree expeditions on the ice-breakers throughout this root, the headed the first Soviet expedition on the North Pole (1937-38), he had been the Editor-in-Chief of the Big Soviet Encyclopedia, the first vicepresident of the Soviet Academy of Sciences, and the deputy of the Supreme Soviet of the USSR. Schmidt had provedhimself an excellent organizer of a set of polar expeditions and other state projects. Then, in the July1941 in the run of the fascist's invasion into the USSR, J. Stalin commissioned Schmidt to organize an evacuation of the Academy of Sciences to the East, and just after this huge work had been successfully fulfilled Stalin dismissed Schmidt from all his official posts.

From early youth Schmidt suffered with pulmonary tuberculosis. In 1943 the illness exacerbated and about 10 years he spent between life and death. Nevertheless he continued to work and offered a new theory of the Earth emergence. In 1930s he was one of the most popular public figures in the Soviet Union. He always had been circled not only by scientistsand pupils but with many of those with whom he stormed the North (winterers, aviators, sea captains, biologists, etc.). I've used his abbreviated vita with only one aim to show that multisided interests and civic stand of Russian intelligentsia on the eve of XX century and later had been their distinguishing feature. Maybe he and many other Russian scientists inherited from their predecessors the role of the discoverers or the pioneers. But there was one principled distinguishing feature: these pioneers in science had always been socially-concerned. They correlate their research interests with the tasks of Russian society development. Therefore, it is not surprising that they themselves and their friends liked classic music, opera, ballet and their scientific gathering often ended with political discussions. Besides, my farther supplied me with book on the Great Geographical Discoveries. Taking these facts together I think that it had been my first lesson on globalization.

A position as a researcher-and-civil activist (or a researcher-and-traveler) had been peculiar to many Russian scientists and scholars of XIX-XX centuries. For example, V. Vernadsky, the author of the Biosphere concept, had initially been a local political activist, then he became a member of the board of the Russian party of the Constitutional Democrats, he wrote a set of programs of science and agricultural development of Russia and so on (Vernadsky, 1995). Well-known the US sociologist of Russian origin P. Sorokin wrote his fundamental work 'Man in calamity' as bio-sociologist (Sorokin, 2004). Many Russian and the US sociologists and writes had initially been the muckrakers, i.e. criminal reporters. That is a one-sided perfectionism in modern sociology and environmental sciences doesn't work.

Now I turn to a brief description of successful social settings of myearly life which had educated me and inspired no less than secondary school, higher institute and other social institutions taken together.

\section{THE IMPORTANCE OF INFORMAL COMMUNICATION}

Nikolina Gora is neither a holyday village nor a housing estate. It is a second place of living suitable for winter season, a type of settlement inherited from the late XIX century with its social and cultural peculiarities well described by A. Chekov well-known Russian novelist. Nikolina Gora established in 1928 is situated in about 40 kilometers from Moscow. As for my family and me, this dachnposelokwas much more important than city life for the reason of its many qualities: the diversity of inhabitants, variety of possibilities for relaxation and sport, and what was most important to me is a natural landscape which surrounded that small summer settlement. In those times I knew nothing 
about social sciences because I'd decided to be a painter. And in that settlement there were some painters who (or their daughters) agreed to give me some lessons in oil painting. But the main feature of this settlement was a high degree of concentration of a variety of artists: composers (S. Prokofiev), pianists, composer and teacher (A. Goldenweiser), singers, actors and so forth and so on. On the other hand, there were many outstanding scientists like Noble Laureate PiotrKapitza, surgeon Sergei Yudin. Despite of the very tense political atmosphere of 1930-50s, practically all doors at Nikolina Gora were open, and we, teenagers literally penetrated everywhere without any barriers.

Nikolina Gora is only one of many similar summer settlements around Moscow and St. Petersburg. In the Soviet Times it had been a developed network of such settlements as well as of hospitals, sanatoriums, rest houses, tourist bases, the Houses of Scientists and so on and so forth. Such rest-andclub systems (with reach libraries) had been a mighty instrument of interdisciplinary communication in a very attractive calm natural milieu. It's curious but in those times the newest books and off-prints have appeared not in libraries but in such libraries and rest-houses. So intensified and diversified communication between the youth and old, the scientists and scholars, the theorists and practitioners, I'd see nowhere more but the UNESCO's headquarters.The information-communication revolution coupled with growing bureaucratic pressure totally destroyed such science-and-human integrating places.

As for me, it had been a lucky chance to have the talks with outstanding Russian scientists and scholars including three Noble Laureates in physics and many other interesting people across the country. And such meetings had repeated many years. For example, the sun of Noble laureate PiotrKapitza, AndreyKapitza, member-correspondent of Russian academy of sciences, a participant of four expeditions to Antarctica, the explorer and discoverer of a giant sub glacialLakeVostok under the Soviet South Polar Station. The talks with prof. A. Kapitza gave me one more impetus to develop a hypothesis of the Earth as the SBT-system. But it is indicative that half-a-century earlier, geochemist academician V. Vernadsky, the author of interdisciplinary Biosphere concept, used the sanatorium Uzkoe as a place of gaining information about the life in all parts of the Soviet Union from the first hands. All Russian scholars and scientists well understand a necessity to gain an integral knowledge.It had been my second lesson on globalization.

Of course, some members of my 'big family' were not the universals. My brother Vladimir and my Uncle Michal had been engineers (academician Michal Kirpichevhad been a specialist in thermodynamics). In my life they had played a no less important role than my parents. Besides their endless kindness and patience,they were not teachers or tutors for me but rather kindly-disposed mentors. Due to their patience I'd learned a lot of practically useful knowledge and things and later during about 40 years I was capable not only to drive a car but repair it if necessary (in those times private car had been a rarity even in Moscow, and repairing had always been a problem).

\section{From Oil Panting to Architecture and then to Multidisciplinary Studies}

Until graduating from secondary school I dreamed of being a landscape painter. At my technicallyoriented secondary school I liked history and English lessons. Entering the Architectural Institute, I continued oil painting (the chairof design and painting was headed by well-known Russian painter Alexander Deineka). But the lucky chance changed my life again. World-known Brazilian architect Oskar Niemeyer visited the Moscow Union of Architects, and my friend and I had been introduced to him. Niemeyer not only forgot about us but began to supply us with unique photos of his works in Brazilia and other materials. We, two Moscow students, began to write a book about him despite numerous sneers. It urged us to study the ancient Portugal architecture and culture. And in 1964, despite these mockers our book was on the shelves. It was mythird lesson of globalization.

Graduating from the Architectural Institute I'd entered the Academy of Architecture of the USSR. My work there had been a routine one, I studied retail networks. In those times there was neither sociology at all nor such notion as networks. But somehow unconsciously I felt that it is interesting although my colleagues have already been famous architects whereas I investigatedan underground of trade relationships. But again a lucky chance! Studying the US shopping centers I suddenly encountered on works of R. Park and R. Burgess and of other Fathers of Chicago School of Human Ecology. It was a bridge between natural and social sciences. And I clearly understood that social 
ecology is extremely interesting and promising research field. A bit later I'd translated into Russian the R. Meier's book 'An Information Theory of Urban Growth' (Meier, 1965) that had also been grounded on network-approach.

\section{A BREAKTHROUGH OF IRON SCREEN}

In July-September 1957, the VI World Festival of Youth and Students under the motto 'For Peace and Friendship' took part in Moscow. It had been a unique international event nevermore repeated in Russia. An absolute public character, mutual trust, and diversity of events and cultures had been its distinguishing features. It had been unbelievable that after the years of dictatorship, secrecy and allembracing fear all doors suddenly became open. It was a feeling that we are suddenly found ourselves into the melting pot of globalization because all seems possible: people, contacts, events, cultures, mass meetings, etc. As for me, it had been surprising twice because I had been working with two young engineers from Brazil about its new architecture my colleague and I had been writing. That is it been not only an impression of a great cultural enterprise but my personal one-to-one contact with the other part of the world.Later on, similar festivals were repeated in the former Soviet Union and Russia several times but the feelings of merging with diversity of thousand people and global cultures had newer emerged. By the way, when Brazilian engineer had visited Moscow for the second time with him had appeared a nice young lady P. Mills, a daughter of world-known sociologists Ch. R. Mills, as I had supposed.In that time she worked in Rio favelas as a volunteer, and it had been my first practical lesson on charity activity. It once more confirmed my conviction that our world is simultaneously great and very small. Later on, working on the project 'Cities of Europe...' I'd realized two more things. First, such gathering of peoples might emerge and disappear here and there, and that is one of the problems that had to be carefully investigated. Second, local gathering i.e. the grassroots is also a problem of modern cities that had to be studied. The actuality ofthese two problems had been confirmed during my participation at the 'Large cities of the world' conference organized by $\mathrm{M}$. Castells in Barcelona in 1965.It were my fourth and fifths practical lessons of globalization.

\section{TRANSFER TO THE ACADEMY OF SCIENCES OF THE USSR}

It really had been a lucky chance to transfer me, an architect to the Institute oriented toward the study of international labor movement and other political affairs. But I had something in my intellectual luggage: knowledge of Anglo-Saxon sociological literature, interest in Brazilian culture and an experience of urban practices, especially in its underground life. I'd entered this Institute in early 1968 and already in 1970 I'd been the initiator of the international conference on the Scientific and Technological Revolution, urbanization and working class. And in 1976 by the invitation of acad. Vl. Sokolov I'd become a participant of the UNESCO's program 'Man and the Biosphere' and coorganizer of the abovementioned 'City of Europe...' project(Deelstra and Yanitsky, 1991). Thus, I simultaneously entered in Russian academic community and world community of sociologists and urban planners. Some Russian commentators called the 1970s as 'long and tedious years.' But for me it had been the years of intensive creative work which gave me a lot of new knowledge and ties with very interesting colleagues across the word. Simultaneously I rented a datcha in summer settlement near Moscow in which I had extremely interestingtalks with two other Noble Laureates, acad. A.M.Prochorov and V.L.Ginzburgand many other interestingscientists and scholars. I'd like to underscore that free talk without any time-table during a walking along the forest vista is sometimes much more fruitful than the presence at any workshop or seminar. My interest to the globalization began to expand not only in width but in depth as well.

\section{A ReSearcher as a Public ACTiVist}

The reverse side of the same coin had been my interest in grassroots activism. Partly it had been stimulated by the M. Castell's book 'The City and Grassroots' with whom I met at the ISA congress in Varna (Bulgaria, 1970), partly it had been inspired by my own interest in the Soviet environmental movement which emerged in early 1960s. Once again: in those times there was no any informationbased communication system between numerous grassroots units across the country as well as later on during the years of perestroika (1987-91s). Finally I understood that network-structured resource and communication systems are the basement of social-structural organization of modern society. And it is simultaneously a real basement of all natural and social processes of the world and a mighty research instrument. In other words, following M. Castells and many others I once again realized that modern world is not only territorially but network-structured as well. Gradually the 'territoriality' (space 
factor) has been converted into time.It has been so called the 'inversion of space effect.' Itwas one more confirmation that the globalization has to be analyzed as a system of various networks.In turn it urged my interest to the metabolic processes within the nature and between it and socially constructed built environment.

Besides, my work as a city planner and urban sociologist taught me that in order to do my work well I had to master at least about 10-12 professions including planning and transportation as such, topography, economy, sociology, some knowledge in construction physics and so on. As my experience in this realm showed, after the long-term process of a neighborhood settling another and very painful process of residents' adaptation to their new flats and apartments begins. Again and again sociologists together with engineers have to resolve rather complicated issues of social, technical, economical, and juridical nature. So being officially an architect, practically I'd to be wellexperienced professional. This integrative approach appeared very useful in my further studies of globalization. Therefore, my interest in the development of abovementioned UNESCO's project'Cities of Europe' with its accent on public participation had not been occasional. But I still didn't know what had been the most important in my fifteen years work: the above research project with participants from 16 European countries orsimply the presence at this global melting pot at the UNESCO's headquarters?Or are both?

\section{ON EMERGENCY CASES IN MY LIFE-SPAN}

It seems to me that European sociologistsare paying insufficient attention to such cases, especially in individual life. Dealing with emergency cases (man-made catastrophes, forest fires, floods, tornados) for many years I always interested not only in the humans' behavior in the midst of such cases but in the adaptation of affected people to extreme stress afterwards. As to me, I consider my life as very happy one in spite of some of some emergency cases, and now I'll try to reflect on my personal reaction on such cases during my life-span.

I have to dividesuch cases in two categories. The former is all-embracing state of emergency like the wars, revolutions or radical changes in habitual mode of living. They are inescapable calamities using the P. Sorokin expression. The latter are my individual emergency cases that had been focused on me personally. Of course, there is no strict division between the above twobecause both categories are took place in an environment which is never totally risky or not. Nevertheless, in the second case a personal reaction on the latter and resources at hand are quite important. One more precondition is an individual preparedness to such critical events, that is an accumulation of experience of the past irrespectively whetherit is your own experience or of those whom you love and trust.But such experience is limited because in every new case the circumstances are new ones.

Until eight years old my life had been true happy. But the invasion of German Fascists in 1941 in the USSR (we name it the Great Patriotic War, 1941-45) had sharply changed my life. We were evacuated in Kazan (the Tatar Republic), my father was absent for month, my mother and sister worked in the military hospital. After several months of severe illnesses I found myself in entirely newand sometimes alien social milieu. And my behavior had been like that of a cat: step by step to investigate my new immediate milieu. It had been right strategy but with some unintended consequences: ones I'denteredinto the den of thieves. This visit had a happy end: I said them that I'm going to the hospital and they gave a bag with cigarettes and sweets.The second case of the first category had been the 'Doctors' Plot' (1952-53) in which a group of Kremlin doctors had been accused in the plot against Stalin and other leaders of the USSR. One of these doctors had been a good friend of our family and their son had been my best fellow from the early childhood. He was immediately dismissed from the Institute, and I had been accused in the loose of political vigilance, and the matter was goingto the arrest. In this case I'd been powerless against a giant political machine and grew torpid.

As to second category of casesof emergency I always tried to mobilize all possible means tolessen the risk or at least to mitigate it. One example is appropriate here. My relationships with the director of the Institute of Public Buildings in which I worked in 1957-66s had been rather tense. The director had been an adherent and propagator of communal way of life repeating the ideas of 1920s whereas I had been a backer of the European approach to urban planning and houses with family apartments. Once, the divergence of our world-views acquired public character, and I had been accused in revision of Marxist-Leninist theory. I was forced to leave that Institute and to transfer to the Institute of the 
International labor movement of the Soviet academy of sciences. My colleagues and me had written a book on urban sociology and submitted it to a publishing house. Director of the former Institute wrote a negative review. We went to the court and had received a one hundred percent honorarium but our book had never been issued.

In the end of this paragraph I'd have to mentionsome ethical aspects. My grandfather, a military surgeon and participants of three wars Feodor Yanitskyhad been a convinced monarchist and an adversary of any violent actions.He never justified a radical political stand of his nephew Vladimir Lichtenstadt. The grandfather's letters from Russian-Japan War (1904-05) full of critics of the politics of Russian liberals. But every month Feodor sent money to imprisoned Lichtenstadt in convict prison (the same did my father Nikolai during horrible 1930s). At the same time Feodor had never been against his daughter's democratic attitudes and activity.On the contrary, he had been very happy when Vera had become a researcher, teacher and public activist simultaneously. My grandmother Elizaveta never followedrevolutionary views of her sisters one of which had been sentenced and died at Siberian convict prison. After her four years work as zemsky doctor in Russian province she fully devoted herself to various kinds of civic activism. It had actually been a volunteer work at the hospitals, tubercular sanatoriums, etc. But Elizaveta's worked as an integrator of a big family by means of intensive letters' exchange. It had been a very important workbecause the members of 'big family' permanently changed their place of work and residence. So the maintenance of this family by means of letter-networks allowed many of its members to survive in the years of the First Russian revolution (1904-07) and in civil war. It's a curious but very important fact: in the run of the Second Russian revolution and civil war (1917-22) railway roots and other means of communication had been broken except the post and telegraph(Yanitsky, 2012).

\section{On ETHics And Cultural Codes}

One more result of my long-term being within academic community was a growing interest to public activity of the scientistsor to science-civic activity of the researchers. The following text is only a brief summary of my view on the issue. From the midst of the XIX century onwards a system of ethic norms of a researcher's behavior began to shape. I call this system the cultural code of a Russian science.

First, the foundations of the code had been formed during the struggle between a rapidly developing Russian scientific community and the state bureaucracy, especially that of responsible for the Enlightenment. Second, a forming of small groups of scientist-and-civil activists' like-minders(they were called themselves as the 'brotherhoods') mushroomed across Russian universities. The response of the state bureaucracy had been tough: many university academics had been dismissed. It had been the initial phase of shaping of the above cultural code. It may be seemed strange but even in 1918, i.e., in the tightest point of civil war in Russia, Vl. Lenin moved a slogan: 'To learn, learn and once more to learn!' And in spite of many political twists and critical events like the WWII this slogan had been valid till the decay of the Soviet Union in 1991. By the way, in 'The Two Captains', one of the most popular Soviet novel of the 1940-60s, this slogan had been reformulated as following: 'To struggle and to search, to find out and not to surrender!'

Second, a necessity to have an individual life plan is it's the second point. It doesn't mean that this plan cannot be changed. On the contrary, as Vernadsky liked to reiterate, 'A scientist must be in the midst of social life.' And he confirmed this principle during his life many times.An individual life plan of a scientist has to be flexible taking into account the changes in natural and social milieu. Practically it means a non-stop education and training.

The third point is a combination of research and practice. Totally-computerized a desk or lab-work is not capable to replace personal experience gained in everyday multisided practice. My half-a-century study of Russian environmentalists showed that a predominant majority of them not only have become serious specialists of national or even of global scale in some environmental issues but continue to maintain their brotherhood on local or global scale. It also means that they could survive in the critical years of Russian perestroika in the1990s. In sum they have to become experienced people capable to work interdisciplinary. Therefore, puritanism or perfectionism had been impossible in Russian scientific community neither before so-called 'great socialist revolution' of 1917 nor after 
it. Russian academics have to be the researchers and public figures simultaneously. Only playing these two roles together some modernization projects had been realized.

Fourth and the most disputable point is a freedom of scientific research. Academician V. Vernadsky, one of the creators of cultural code of Russian science, insisted on this point. But in essence he always went after the development of global, national and local practices. As for me, this point means to be on the edge of global and Russian developments and issues simultaneously. Besides, it means not to trust to the Big Data researches without the knowledge about their methodological underpinnings. The right way to gain a valid knowledge is to combine quantitative and qualitative investigations. But the best way is to develop the research methods which allow us to monitor the ongoing processes and changing structures and networks in their entire complexity and permanent transformations.

Fifth, we are now witnessing the beginning of the process of merging of social and natural sciences. As for me, it is absolutely timely process because there is no man - nature dichotomy. A humanity activity is rapidly transforming our planet into a highly complex and unstable socio-biotechnical system(Yanitsky, 2016).Half-a-century ago Vernadsky said that the humanity had become a mighty geological force. But recently a man has become suchmighty complex force burdened with global risks. Does the new integrated cultural and ethical code of Russian academics needed? It is a very controversial situation. On the one hand, the above complex systems urge scientific community to develop an adequate ethic system and interdisciplinary language. On the other hand, the technocrats united with global stakeholders see a digitalization as universal matrix for any purposes. As concerns to ethical code of Russian humanities, especially of those which relate to cultural environment, I think that the best articulation of it belongs to Russian historian academician D. Likchacev (1982).

Sixth and very acute as well is a resistance against any administrative matrix imposed on the researchand-development processes. The matter is that any bureaucratic structure besides its decision-making and administrative functions gains profit from a construction of new and new codes be it directives or temporary instructions. According my approximate calculations a clerk's month salary in any administrative unit for science government as social institution is fifteen times more than ordinary professor (I'm not included in thesecalculations privileged universities and professional or sectorial national academies). It doesn't mean that nothing has changed but I wrote about my life and my times. As one can see the above sketch of cultural and ethical code of Russian academics is different from that of developed by the US sociologist prof. R. Merton (Merton, 1949).

\section{CONCLUSION}

I undertake the excursion in my own life and my 'big family' past because it reflects a state of affairs in intellectual-sociocultural milieu during about eighty years in the former Soviet Union and current Russia. Of course, a variety of other trajectories of a life-story is existed. The forces which shaped me as a personality were as following: my 'big family', its history, moral stands and social and public activity, a periodical change of scientific and cultural milieu, and a set of happy chances (opportunities) and emergency situations.Such cases were the excellent teachers for being an experienced man. Anyhow, civic activism is an important bridge between professional and public activity. And sometimes civic activists turned into professionals and vice versa because the difference between a desk-modelling of critical events and actual emergency situations has become conditional or Janus-like.

As to research methods in this very area of studies, I remain an adherent of qualitative analysis. Social statistics including the Big Data methods are not subjected to verification of their initial databaseincluding compiling the guides, the methods of selection of strata of respondents, etc. In this very case social statistics levelled very important peculiarities of individuals and their particular environment. Widely usedtypologies like big city, small city and the like are two rough for the study of behavior of micro-sociological agents. For example, I never saw a research findings taking into account a size and composition of a particular family.

We are the scientists, scholars and civil activists communicate not only via the Internet but still personally, one-to-one as well. My eighty year experience to be within the 'club' of such multi-sided researchers, artists and experienced people, sometimes not well educated but having a rich personal multidisciplinary knowledge convinced me that we are much closer mentally that it seems to the first glance. Besides, to be simultaneously a researcher and a pathfinder it is a long Russian tradition. 
Sooner or later the very life forces us to become multidisciplinary ones or at least to be capable to understand each other.

Under the pressure of the Fourth technological revolution we are all oriented to a future. Nevertheless, the past has not disappeared from our life. Capitalism has exerted a substantial impact on 'big families', the gap between the youth and the old is rapidly growing. It is impossible to compare a behavior of individuals of twenty and sixty years old, they have been shaped in entirely different sociocultural environment. But to compare their moral and ethical stands is still possible.

To restore the 'big family'sstructure (under a new conditions!) two things are needed: a definite and well-substantiated immediate aims and ultimate goals of a society's development and sharp reduction of material and social inequalities. That is, to be armed with the ideology of modest consumption. Therefore, it seems to me that (in moral terms) the past taken as a concept of the 'big family' is still valid and it is true not only in relation to a particular family but to humanity as a whole. The processes and conflicts peculiar to particular families and communities are now characteristic to humanity as a whole. As to particular families, the moral ties between the young and old are usually active during two generations (i.e. about a half-a-century) then they are transforming into a fact of a family history, written ororal or as the memoires.

To my mind, it is dangerous if a global human community will be represented by two adversarial parts only that isby a few global stakeholders and myriads of placeless individuals who new neither their small Motherland nor family roots. In this case a globalization process has a risk to turn into the Brownian movement.

Finally, I suppose that cultural and ethical code of Russian academics briefly sketched above will substantially change in the coming few decades. The science-practice relations are already under growing pressure of global business, power structures and media. Plus time pressure, changing relationships between the North and the South and, of course, the domination of technocrats in all spheres of social life. And the most important question: will Russian scientific code remains or it will be quickly merged by integrative processes within global scientific community? But it is a theme for another article.

\section{REFERENCES}

[1] Deelstra T. and Yanitsky O., eds. 1991.Cities of Europe: The Public's Role in Shaping the Urban Environment. Moscow: MezhdunarudnyeOtnosheniya.

[2] Likchacev D. 1982.Ekologiyakul'tury [Ecology of a culture] Znznie-Sila, no 6: 22-24.

[3] Meier R. 1965. The Communication Theory of Urban Growth. Mass.: MIT Press.

[4] Merton R.K. 1949. Social theory and social structure. New York: The Free Press.

[5] Schmidt Vera. 1924. PsychanalytischeErziehung in Sowietrussland. Leipzig, Zürich, Wien: InternationalerPsychoanalytischerVerlag.

[6] Sorokin P. 2004. Golodkak factor [Hanger as a factor]. Moscow: Academic Project.

[7] Vernadsky V. 1995.Publicisticheskiyestat'i[Collection of publicist essays]. Moskva: Nauka.

[8] Yanitsky O. 2012. SemeinayaKhronika.1852-2002. [Family Chronicle. 1852-2002]. Moscow: LVS Publ. House.

[9] Yanitsky, O. 2012. A Primary Eco-Structure: The Concept and its Testing. Social Analysis, Vo.2 No 2, pp. 7-24.

[10] Yanitsky O. 2016.Sotsiobiotechnicheskiesystemy: novyivzglyadnavzaimodeistviechelovekaiprirody [Sotsiologicheskayanaukaisotsial'nayapraktika], Vol. 4, no 3: 5-22. Available at: http://manuscript.sciknow.org /uploads /ojssr/pub/ojssr_140963345.pdf

Citation:YANITSKY Oleg Nikolaevich. "Russian Environmentalist Oleg Yanitsky: Reflections on My Own Life-Story "International Journal of Humanities Social Sciences and Education (IJHSSE), vol 4, no. 12, 2017, pp. 118-126. doi:http://dx.doi.org/10.20431/2349-0381.0412015.

Copyright: () 2017 Authors. This is an open-access article distributed under the terms of the Creative Commons Attribution License, which permits unrestricted use, distribution, and reproduction in any medium, provided the original author and source are credited. 